\title{
Developed Countries Agricultural Subsidies and Cotton Production in Burkina Faso: An Analysis Using the Vector Autoregressive Model (VAR)
}

\author{
Aboube Mahaman Laouan \\ Faculté des Sciences Economiques et de Gestion (FSEG). Université Abdou Moumouni, Niamey, Niger \\ Email: Aboube6@yahoo.fr
}

How to cite this paper: Laouan, A. M. (2021). Developed Countries Agricultural Subsidies and Cotton Production in Burkina Faso: An Analysis Using the Vector Autoregressive Model (VAR). Modern Economy, 12, 46-68.

https://doi.org/10.4236/me.2021.121003

Received: December 5, 2020

Accepted: January 25, 2021

Published: January 28, 2021

Copyright $\odot 2021$ by author(s) and Scientific Research Publishing Inc. This work is licensed under the Creative Commons Attribution International License (CC BY 4.0).

http://creativecommons.org/licenses/by/4.0/

\section{(c) (i) Open Access}

\begin{abstract}
For several years, cotton prices have been experiencing a sustained decline on the world market. For cotton-producing developing countries, this low price is the result of subsidies granted by developed countries, particularly the United States and the European Union to their producers. As a result, these developing countries expect substantial gains in trade and economic development once the subsidies are ended. This article aims to analyze the effect of U.S. and European subsidies on the production of Burkina Faso, one of Africa's leading cotton exporters whose cotton sector is currently experiencing serious difficulties. The data used in this thesis are secondary data, drawn from existing databases or specialized journals and using an econometric model, the Vector Auto Regressive (VAR) model, the analysis shows that a negative and significant impact of subsidies on cotton production in Burkina Faso is highlighted. The consequences of the end of subsidies on the Burkinabe economy should be positive. Analysis by the VAR model through impulse response functions shows that U.S. and European subsidies negatively affect Burkina Faso's cotton production and that these impacts do not occur directly but through the world price of cotton. Therefore, the State, cotton companies and producers, the three main actors in the sector, should see their situation improve simultaneously in the event of subsidy removal.
\end{abstract}

\section{Keywords}

Cotton, American and European Subsidies, Africa, Burkina Faso

\section{Introduction}

The effect of the agricultural policies of Northern countries on the world prices 
of different products (particularly cotton) is still the subject of intense debate. For several years, the subject has been at the heart of North-South trade negotiations, particularly those undertaken within the World Trade Organization (Doha Conference, Cancun Conference). Studying the functioning of the cotton sector through the case of Burkina Faso, a cotton producer since 1920 in what was then the colony of Upper Volta, helps us understand the complex relationship that today's agricultural raw material producing countries have with the (Northern) countries that purchase and transform these raw materials into finished products. Countries including Burkina Faso.

For many of these cotton-producing countries, including Burkina Faso, the issue is crucial. Indeed, for this country, cotton is one of the leading sources of foreign exchange for commodity exports each year ${ }^{1}$. The problem is all the more important for these countries because cotton prices are currently very low.

According to $\mathrm{ICAC}^{2}$ (International Cotton Advisory Committee), the amount of aid paid to cotton production worldwide in the 2017/18 season reached 5.9 billion dollars, an increase of $33 \%$ compared to the $2016 / 2017$ season.

Cotton is therefore likely to be the only important agricultural product for which African least developed countries compete directly with industrialized countries on the world market and that the policy of support for cotton producers in industrialized countries is not compatible with their policy of supporting the development of least developed countries including Burkina Faso.

The cotton sector is hit by the deep crisis due to subsidies granted by developed countries to their producers. These granted subsidies keep cotton production at profitable levels in industrialized countries, reducing the possibilities for Developing Countries (DCs) to export to markets of countries that grant subsidies and divert their exports to third countries.

According to statistics from the US Department of Agriculture (September 2019), for $2019 / 2020$ agricultural campaign, world cotton production is projected at a level of 124.9 million bales. The four main producing countries namely China, India, the United States and Pakistan account for nearly three-quarters of global volumes. This market concentration, which has strengthened in recent years, must be put into perspective by considering the impact of agricultural policies implemented by the main producing countries as well as climatic or health hazards and their influence at the global level.

For the 2019-2020 campaign, Burkina Faso produced 464,000 tonnes of cotton, behind countries such as Benin (714,714 tonnes), Mali (700,000 tonnes) and Côte d'Ivoire (490,470 tonnes) while a few years ago, the country was the leading producer of African cotton.

However, subsidies to productions in western countries constitute a distorting factor. They resulted in placing on the world market of subsidized surpluses at low prices ${ }^{3}$, thus entering into direct competition with agricultural exports from

${ }^{1}$ Source: UNCTAD secretariat.

${ }^{2}$ International Cotton Advisory Committee.

${ }^{3}$ According to ICAC to the ICAC, this surplus is estimated for the 2014-2015 campagn at 13.3 million tonnes. 
developing countries, in particular cotton. These agricultural policies are based on a battery of instruments including in particular guaranteed minimum prices, market organizations and supply management mechanisms (quota for example), supply and financing mechanisms including many forms of subsidies.

The general problem is therefore the subsidies granted by the countries of the North to their cotton producers and its effects on the economies of producing developing countries like Burkina Faso.

Before presenting the results of the econometric estimation, however, we will first review the studies devoted to the impact of American and European aid on the international cotton market. These studies can be classified into two groups according to the type of model used: partial equilibrium models (static and dynamic) with one or more products and general equilibrium models.

\section{Review of Existing Models on Measuring the Impact of Subsidies and Protection Measures on the World Cotton Market}

Many studies have been devoted to the impact of American and European aid on the international cotton market. These studies can be classified into two groups depending on the type of model used: partial equilibrium models (static and dynamic) with one or more products and general equilibrium models.

\subsection{Single-Market Partial Equilibrium Models}

\subsubsection{Goreux's Study}

The author starts from a relatively simple model of the world market reduced to cotton supply and demand. From a world equilibrium price established by the confrontation of these functions of world supply and demand, it simulates an elimination of subsidies over the last five years before the study. The base period thus corresponds to the average from 1997/98 to 2001/02.

The elimination of subsidies leads to a reduction in the world export supply, with previously subsidized producers only touching the world price. A new equilibrium price higher than the previous one is established in the world market, depending on world demand and new supply. The simulations carried out with this model give, for the elasticities of supply and demand retained, an increase in the world price ranging from $7.5 \%$ to $11.4 \%$ over the period 1997/1998 2001/2002. The export earnings gains for West and Central African countries amount to $\$ 250$ million depending on the parameter values (elasticities).

\subsubsection{Tokarick's Study}

The study (Tockarick, 2003) concerns the majority of agricultural products and not specifically cotton while having a partial equilibrium structure. The model assumes the homogeneity of cotton at the global level. The cotton demand functions depend only on the cotton price, all other factors (income, population, etc.) are considered constant. The same assumption is made for the supply functions: climatic factors, risk and constraints at the production level are not explicitly 
taken into account. For each country, net exports are given by the difference between domestic production and consumption ${ }^{4}$. The elasticities of the export supply selected vary from 1.5 to 10 and those of import demand are fixed at 0.75 .

Due to its partial equilibrium structure, the market factors are not explicitly modeled. However, the support measures for the purchase of inputs are taken into account in the producer price.

Using data from the United States Department of Agriculture and taking the year 2000 as the reference period, the author performs three simulations concerning American aid and successively focusing on: the elimination of agricultural subsidies export, the elimination of production subsidies and the elimination of all support measures.

The three simulations respectively give an increase in the world cotton price of $0.8 \% ; 2 \%$ and $2.8 \%$. Note that the model does not include import tariffs or quotas. Likewise, only US subsidies are taken into account.

\subsubsection{The ODI (2004) Study}

This study is based on (Goreux, $2003 \mathrm{abc}$ )'s model revised at two levels. Initially, the hypothesis of homogeneity of cotton traded internationally is relaxed in favor of that of fragmented markets. In this configuration, the structure of trade is fixed, countries trade only with their historical partners after the elimination of support measures. The hypothesis of a unified market is relaxed, on the one hand, due to the differences in quality existing between the different varieties of cotton (length of the fiber, color, resistance, color, adhesiveness, presence of foreign bodies, etc.) and on the other hand, due to factors linked to the supplying country (transport and shipping facilities, the country's reputation for meeting deadlines, regularity of the offer, etc.). The postulate of fragmented markets which refers rather to situations of imperfect competition type, may, even if it seems reasonable, become problematic in the event of significant price variations. It may indeed be that large variations in the relative prices of the various cottons traded lead some importers to change supplier country.

In order to avoid the systematic attribution of the same value of the elasticity of supply to all countries, the authors estimate them individually using a supply function of (Nerlove, 1958) with partial adjustment of supply. The supply function includes the price of competing cotton products in the countries considered.

The model also includes supply-side constraints, particularly for Central Asia and Australia where water availability constraints, exacerbated by drought, compromise irrigation capacities. The authors carry out four simulations consisting in the elimination of American, European and Chinese aid, and based respectively on the following assumptions: 1) unified market and elasticity of supply (0.5) common to all countries (U/U);2) fragmented market and elasticity

${ }^{4}$ Indeed, all other thing being equal, the good being homogeneous and the single price, a country cannot be both importer and export. 
of supply common to all countries $(\mathrm{F} / \mathrm{U}) ; 3)$ unified market and elasticity of supply specific to each country (U/D); and 4) fragmented market and elasticity of offer common to all countries (F/D).

The results indicate a greater impact on the world price as the market is fragmented. Similarly, relaxing the assumption of common elasticities leads to a larger price increase. The common supply elasticity $(0.5)$ is indeed higher than the average of the elasticities obtained separately. The rigidity thus introduced tends to overestimate price effects.

\subsubsection{The ATPSM Model of Poonyth et al. (2004)}

This study is based on the Agricultural Trade and Policy Simulation Model (ATPSM), jointly developed by FAO and UNCTAD. The ATPSM model is a static partial equilibrium model that can be extended to several products and regions. However, the version used by Poonyth et al. corresponds to a cotton "sub-model".

The model assumes product homogeneity (perfect substitution between imported and domestic cotton). The model also assumes a complete transmission of price fluctuations between the international and domestic price. Supply and demand for cotton depend solely on prices. In addition to the subsidies that come from notifications made to the WTO, the study takes into account all trade restrictions (tariffs, quotas, quotas) through their ad valorem equivalent.

The authors proceed to the elimination of all subsidies and trade-restrictive measures through five simulations by modifying the values of the elasticities of supply and demand. The price increases observed with respect to the reference period (1997-1999) are very modest and range from 3.1 to 4.8 percent depending on the values of the elasticities. Price changes are $66 \%$ due to the elimination of U.S. subsidies and 33\% due to the elimination of European Union subsidies. Poonyth et al. also simulate for comparison purposes the previous scenarios using the ICAC database instead of the notifications made by countries to the WTO. This comparison is indeed interesting as it allows the inclusion of Chinese aid. In this case, the removal of subsidies worldwide leads to an increase in the price of the product.

\subsection{Partial Multi-Product Partial Equilibrium Models}

\subsubsection{The FAPRI ${ }^{5}$ Study}

The study is based on the multi-product dynamic partial equilibrium model of the same institute. Support measures from all countries are considered. The new European measures are taken into account in the scenarios after 2002 until 2012. The study also integrates China's accession to the WTO in 2001. However, for the United States, the projections used were prepared in January 2002 and are therefore based on the 1996 FAIR Act and not on the 2002 law, let alone the 2008 law. It should also be noted that all the parameters of the model (in partic-

${ }^{5}$ Food and Agricultural policy Research Institute, affiliated with the University of Missouri and Iowa. 
ular the elasticities) come from econometric estimations.

The area planted to cotton in the U.S. (like that of the other eleven commodities considered) depends on the producer's expected net income. It is defined as the difference between income from cotton marketing plus subsidies and production costs. European subsidies are converted into a producer price equivalent.

The simulated scenario consists of the elimination of all support measures (trade measures and production support measures). The elimination of support leads to an average increase in the world cotton price of 11.44 percent over the period 2002-2012. The elimination of trade measures alone leads to a price increase of 2.93 percent over the same period.

The FAPRI study is the first attempt to address the issue of subsidies within a multi-product partial equilibrium framework. Competing cotton crops are taken into account in the U.S. supply model. Moreover, the decision variable for producers is their expected net income, not the price.

\subsubsection{Sumner's Study}

The model consists of two blocks, with the US market on one side and the rest of the world on the other. The U.S. market is modeled at a disaggregated level with six major production regions. As in the FAPRI model, the U.S. grower makes the decision to plant based on the expected net income from the product. Expected prices are described by a process of adaptive anticipation as in (Nerlove, 1958). The six aid measures (marketing loans and loan deficiency payments, direct aid, counter-cyclical payments, subsidies for insurance premiums) are taken into account in the calculation of the producer's expected net income. However, contrary to the FAPRI study, Sumner introduces parameters that take into account the more or less decoupled nature of the various aids.

First, the author simulates the elimination of each of the individual measures and then proceeds to the removal of the aid package. The reference period is the average of the 1999/2000 and 2000/01 campaigns for the static part and the 1999-2007 period for the dynamic part.

The removal of the six support measures reduces U.S. cotton production by 28.7 percent over the period 1999-2002. At the individual level, trade loans have the greatest impact on production (15.6 percent reduction in production). As for the world cotton price, over the period 1999-2002, the elimination of subsidies leads to an increase of $12.6 \%$. In dynamic terms, the price increases by an average of $11.6 \%$ over the period $1999-2007$ and production falls by $27.4 \%$.

\subsubsection{The Study by Pan et al. (2004)}

This research, conducted by the University of Texas ${ }^{6}$ Cotton Economics Research Center, adopts a dynamic partial equilibrium framework very similar to that of (FAPRI, 2002) and (Sumner, 2003). However, unlike these two studies, substitution effects between cotton and synthetic fibers are taken into account

${ }^{6}$ Texas Tech University. 
through specific equations (especially for polyester). The model also takes into account the interactions between the raw fibre market and the textile market. Thus, per capita fiber consumption is explicitly modeled through the introduction, in particular, of income as an explanatory variable. Stocks are also integrated into the model.

As in the FAPRI model, export and consumption subsidies enter directly and linearly into the equations defining exports and domestic cotton consumption, respectively.

The scenarios tested involve the elimination of the 5 support measures that the U.S. government provides to cotton producers (direct payments, countercyclical payments, marketing loans, export and consumption subsidies) over the period 1999-2000 to 2002-2003. The results indicate, over this period, a 5.67\% drop in production and a $2.43 \%$ increase in the world price if all support measures in the United States were eliminated (excluding subsidies for insurance premiums). Using the same exercise over the period 2003-2003 to 2007-2008 and assuming that the support programs will be maintained, the world price increases by an average of $1.58 \%$.

\subsection{General Equilibrium Models: The Study by Reeves et al. (2001)}

In the literature dealing with the effect of subsidies on the cotton market, the study by (Reeves et al., 2001) is, to our knowledge, a unique attempt at general equilibrium modelling. It was conducted by the Centre for International Economics ${ }^{7}$ at the request of the Australian Cotton Research and Development Corporation to study the impact of US support measures on the Australian cotton market.

Two models are used: the Global trade analysis project (GTAP) model to assess the impact of full market liberalization on the world price of cotton and the Centre for International Economics Multifiber Agreement model to quantify the impact of liberalization of the U.S. textile market on the Australian industry.

The GTAP model is a multi-sector and multi-region model (45 regions and 50 sectors). Because of its general equilibrium nature, it takes into account the rest of the economy, particularly the textile market. This allows the authors to go beyond the raw cotton sector by simulating other scenarios such as the elimination of trade barriers (tariff and non-tariff) prevailing in the textile and clothing market.

The base year used is the 1998/1999 season. For this campaign, the data used (ICAC data) indicate an average support of 14 cents/pound of cotton for the United States, 82 cents for the European Union and 27 cents/pound for China.

The three simulated scenarios deal successively with: 1) the elimination of tariffs and quotas on all textiles and clothing; 2) the elimination of all support measures for the cotton sector (producer support, export subsidies, import ta-

${ }^{7}$ Australian private research center. 
riffs); 3) the combination of the two previous scenarios.

The main conclusion that emerges from this study is the very strong influence of domestic support on the world price, far ahead of trade restrictions on textiles and clothing.

It should be noted that, as far as all these studies are concerned, there is a great variability in the results, particularly with regard to the price response. Indeed, depending on the model, the increase in the world price following the abolition of subsidies is between $2.30 \%$ and $28 \%$. This relatively wide range of results can be explained by numerous factors related, among others, to the structure of the models, the reference periods chosen, the databases used (amount of subsidies) and the values of the parameters retained.

\section{Presentation of the Analysis Model}

\subsection{The VAR Approach (Bayesian)}

VAR models were introduced by (Sims, 1980), particularly the part concerning the didentification techniques. For Sims, the didentification techniques proposed for simultaneous equation models are based on ad hoc restrictions and therefore suffer from a certain number of inadequacies. An a priori too strong restriction is made on the parameters.

All the variables are thus a priori endogenous, and the possible exogeneity of one of them can be tested statistically using causality tests. In this sense, VAR models can be seen as "a-theoretical" econometrics and exclusively oriented towards forecasting (Fève, 2005). These models are therefore considered to be forecasting tools, looking to the future and making it possible to study what would happen in the future if a shock were to occur at the present time. It is then possible to easily carry out forecasting exercises at different horizons for macroeconomic variables based on the recursive representation of the VAR model without having to make additional assumptions about the economic environment.

Thus, the response functions of macroeconomic variables to structural shocks identified by the VAR model constitute a reference that any theoretical model must reproduce as well as possible.

The only attempt to formalize econometrically the impact of subsidies on price using a VAR model is the study of (Shepherd, 2004). This study, which is based on the wool market model of (Piggott \& Whalley, 1980), uses a classic $\mathrm{VAR}^{8}$ model to analyze the effect of US subsidies on the price of cotton and concludes that there is no impact. Two major limitations characterize this type of exercise, however. Indeed, whether it is the original approach of (Piggott \& Whalley, 1980) or that of (Shepherd, 2004), VAR models are extremely data intensive and require series with significant time depth. This data requirement is due to the fact that the number of parameters to be estimated increases very quickly with the size of the model (number of equations and number of lags associated with each variable), which makes estimators less accurate over small

${ }^{8}$ By classic, we mean the "frequentist" approach opposed to the Bayesian method. 
samples (Runkle, 1987). A model with $\mathrm{N}$ endogenous variables and $\mathrm{P}$ lags thus implies the estimation of N2P parameters. Similarly, the relatively small number of degrees of freedom makes the power of standard tests very low. To overcome these limitations logically requires the use of tools adapted to small samples. By combining a priori knowledge of the parameters and the information contained in the data, Bayesian statistics provides such a framework. In this field, the reference works are those of (Zellner, 1971) and (Leamer, 1972), extended to VAR models by (Litterman, 1980), and (Doan, Litterman, \& Sims, 1984). Moreover, unlike the classical approach, the estimation of a VAR model in the Bayesian universe does not require the stationarity of the variables defining the process (Sims, Stock, \& Watson, 1990) and (Canova, 2003).

\subsection{The Selected Model}

This $\operatorname{VAR}(q)$ model is presented in matrix form as follows: $Y_{t}=\alpha^{i}+\sum_{t=1}^{q} \beta_{i} Y_{t-i}+\varepsilon_{t}$ In developed form we have:

$$
\begin{aligned}
E B_{t}= & \alpha^{E B}+\sum_{t=1}^{q}{ }_{E B} \beta_{i}^{E B} E B_{t-1}+\sum_{t=1}^{q}{ }_{E B} \beta_{i}^{P M} P M_{t-1}+\sum_{t=1}^{q}{ }_{E B} \beta_{i}^{P B} P B_{t-1} \\
& +\sum_{t=1}^{q}{ }_{E B} \beta_{i}^{s e} S E_{t-1}+\sum_{t=1}^{q}{ }_{E B} \beta_{i}^{S A} S A_{t-1}+\sum_{t=1}^{q}{ }_{E B} \beta_{i}^{P M C} P M C_{t-1}+\varepsilon_{t}^{E B} \\
P M_{t}= & \alpha^{P M}+\sum_{t=1}^{q}{ }_{P M} \beta_{i}^{E B} E B_{t-1}+\sum_{t=1}^{q}{ }_{P M} \beta_{i}^{P M} P M_{t-1}+\sum_{t=1}^{q}{ }_{P M} \beta_{i}^{P B} P B_{t-1} \\
& +\sum_{t=1}^{q}{ }_{P M} \beta_{i}^{s e} S E_{t-1}+\sum_{t=1}^{q}{ }_{P M} \beta_{i}^{S A} S A_{t-1}+\sum_{t=1}^{q}{ }_{P M} \beta_{i}^{P M C} P M C_{t-1}+\varepsilon_{t}^{P M} \\
P B_{t}= & \alpha^{P B}+\sum_{t=1}^{q}{ }_{P B} \beta_{i}^{E B} E B_{t-1}+\sum_{t=1}^{q}{ }_{P B} \beta_{i}^{P M} P M_{t-1}+\sum_{t=1}^{q}{ }_{P B} \beta_{i}^{P B} P B_{t-1} \\
& +\sum_{t=1}^{q}{ }_{P B} \beta_{i}^{s e} S E_{t-1}+\sum_{t=1}^{q}{ }_{P B} \beta_{i}^{S A} S A_{t-1}+\sum_{t=1}^{q}{ }_{P B} \beta_{i}^{P M C} P M C_{t-1}+\varepsilon_{t}^{P B} \\
S E_{t}= & \alpha^{S E}+\sum_{t=1}^{q}{ }_{S E} \beta_{i}^{E B} E B_{t-1}+\sum_{t=1}^{q}{ }_{S E} \beta_{i}^{P M} P M_{t-1}+\sum_{t=1}^{q}{ }_{S E} \beta_{i}^{P B} P B_{t-1} \\
& +\sum_{t=1}^{q}{ }_{S E} \beta_{i}^{s e} S E_{t-1}+\sum_{t=1}^{q}{ }_{S E} \beta_{i}^{S A} S A_{t-1}+\sum_{t=1}^{q}{ }_{S E} \beta_{i}^{P M C} P M C_{t-1}+\varepsilon_{t}^{S E} \\
S A_{t}= & \alpha^{S A}+\sum_{t=1}^{q}{ }_{S A} \beta_{i}^{E B} E B_{t-1}+\sum_{t=1}^{q}{ }_{S A} \beta_{i}^{P M} P M_{t-1}+\sum_{t=1}^{q}{ }_{S A} \beta_{i}^{P B} P B_{t-1} \\
& +\sum_{t=1}^{q}{ }_{S A} \beta_{i}^{s e} S E_{t-1}+\sum_{t=1}^{q}{ }_{S A} \beta_{i}^{S A} S A_{t-1}+\sum_{t=1}^{q}{ }_{S A} \beta_{i}^{P M C} P M C_{t-1}+\varepsilon_{t}^{S A} \\
P M C_{t}= & \alpha^{P M C}+\sum_{t=1}^{q}{ }_{P M C} \beta_{i}^{E B} E B_{t-1}+\sum_{t=1}^{q}{ }_{P M C} \beta_{i}^{P M} P M_{t-1}+\sum_{t=1}^{q}{ }_{P M C} \beta_{i}^{P B} P B_{t-1} \\
+ & \sum_{t=1}^{q}{ }_{P M C} \beta_{i}^{s e} S E_{t-1}+\sum_{t=1}^{q}{ }_{P M C} \beta_{i}^{S A} S A_{t-1}+\sum_{t=1}^{q}{ }_{P M C} \beta_{i}^{P M C} P M C_{t-1}+\varepsilon_{t}^{P M C} \\
&
\end{aligned}
$$

with: $Y_{t}$ the vector of endogenous variables, $\alpha$ vector of constants, $q$ the number of delays. For the use of the model all the variables are expressed in lo- 
garithm with: $E B_{t}=$ Burkina Faso cotton exports; $P M_{t}=$ world cotton production; $B P_{t}=$ Burkina Faso cotton production; $S E_{t}=$ European subsidies; $S A_{t}=$ US subsidies and $P M C_{t}=$ world cotton price.

\subsection{Choice and Definition of Variables}

The model therefore includes 6 variables. Subsequently we will use the following notations for these variables:

Burkina Faso's cotton exports (EXPB): these represent Burkina Faso's total cotton exports. They are expressed in thousands of bales ${ }^{9}$.

Burkina Faso cotton production (PDB): it is expressed in thousands of bales and represents the quantity of cotton produced by Burkina Faso.

World cotton production (WCP): expressed in millions of bales and represents the quantity of cotton produced worldwide.

World Cotton Price (WCP): is the world cotton price approximated by Cotlook's A-index..$^{10}$ This index expressed in US cents per pound ${ }^{11}$ is the average of the five lowest quotations among a set of representative quotations of very diversified origins, reported at the CAF North-Europe stage.

This variable is important because the distortions in the cotton market refer mainly to the fall in world cotton prices.

- U.S. subsidies to cotton producers (AUSA): U.S. subsidies, expressed in millions of dollars, are approximated by direct government payments of cotton as shown in the U.S. and States Farm Income Data (include calendar-year data on direct government payments).

- European aid (subsidies) to cotton producers (AUE): European subsidies are approached by the aid for cotton production. They are also expressed in millions of dollars.

U.S. aid (subsidies) to cotton producers (AUSA) and European aid (subsidies) to cotton producers (AUE) are the key variables in the model, as they are considered to be at the origin of the distortions observed on the world cotton market but also on Burkina Faso's cotton production.

It should be noted that the conversion into dollars of European grants expressed in Euros was possible thanks to the historical exchange rate databases available on the website: http://www.oanda.com/.

\subsection{Data Sources}

The data covers the period from 1982 to 2017. They are secondary data, drawn from existing databases or specialized journals. The variables used are then taken from a variety of sources. For example:

\footnotetext{
${ }^{9}$ Bale is equal to $480 \mathrm{lb}$. The pound (pound or $\mathrm{lb}$ ) is an Angloxonian unit of measurement which is equal to $0.4536 \mathrm{~kg}$.

${ }^{10}$ Cotlook's A Index is the most frequently cited indicator of the average level of international prices. The A-Index is calculated by the employees of Cotlook Ltd, a private company in Liverpool (UK), which receives price information from both buyers and sellers of cotton from different origins.

${ }^{11}$ The cent is the hundredth division of the dollar ( $\$ 1=100$ cents).
} 
- Burkina's cotton exports, Burkina's cotton production, world cotton production and the world cotton price approximated by Cotlook's A-index are taken from Burkina Faso's 2017 statistical yearbook, the ICAC (ICAC) and Index mundi's website (specifically https://www.indexmundi.com/).

- U.S. subsidies come from the U.S. and State Farm Income Data. (Include calendar-year data on direct government payments): from 1982 to 1995 from (https://www.ers.usda.gov/data/FarmIncome/finfidmu.htm\#payments) and from 1996 to 2017 from (https://www.ers.usda.gov/Briefing/FarmIncome/Data/GP_T7.htm).

- European subsidies between 1982 and 2002 come from the "Official journal of the European Union, Special Report N ${ }^{\circ} 13$ /2003", Table 4 and those between 2003 and 2017 come from the Directorate General for Agriculture (DG AGRI).

Since the data coming from different sources are measured in the same way with the same unit, they are therefore used as taken.

\section{Analysis and Interpretation of Results}

The estimation of the model and the interpretation of the simulation results will be the subject of this point.

\subsection{Study of the Stationarity of the Variables}

The Phillips Perron test was used to study the level of integration of the variables. Indeed, this PP test seems to us to be very appropriate because it is built on a nonparametric correction of the Dickey-Fuller statistics to take into account heteroskedastic errors. Table 1 summarizes the results of the unit root tests applied to all the variables.

Table 1 shows that the variables LEXPB, LPDM, LAUSA, LAUE and LPRMC are stationary in the first difference. While the variable LPDB is stationary in second difference.

\subsection{Study of the Cointegration of Variables}

At this level because of the different orders of integration of the variables, we used Johansen's test for this estimation. This test allows us to know the number of cointegrating relationships. Johansen (1988) proposes maximum likelihood

Table 1. Unit root tests: $\mathrm{I}(\mathrm{n})^{12}$.

\begin{tabular}{ccccccc}
\hline Variables & LEXPB & LPDM & LAUSA & LAUE & LPDB & LPRMC \\
\hline PP & -4.122 & -5.827 & -3.314 & -4.191 & -5.816 & -5.266 \\
CV & -2.798 & -2.797 & -2.985 & -2.798 & -2.997 & -2.889 \\
Résultats & $\mathrm{I}(1)$ & $\mathrm{I}(1)$ & $\mathrm{I}(1)$ & $\mathrm{I}(1)$ & $\mathrm{I}(2)$ & $\mathrm{I}(1)$ \\
\hline
\end{tabular}

Source: Author, based on data estimation.

${ }^{12}$ Means integrated of $\mathrm{n}$ order. 
estimators to test the cointegration of series. He performs a test of the cointegrating rank. The Johansen's method for determining $r$, the number of cointegrating equations used here can be interpreted as being an estimator $\hat{r}$ of the true number of cointegrating equations $r$. The method starts testing at $r=0$ and accepts $\hat{r}$ the first value of $r$ for which the statistic fails to reject the null hypothesis (if the statistic is less than its $5 \%$ critical value) that there are no more than $r$ cointegrating relations.

Table 2 presents a summary of Johansen's cointegration test.

Then, as indicated in Table 2, the cointegration rank is 3. The variables $\log (\mathrm{EXPB}), \log (\mathrm{PDM}), \log (\mathrm{AUSA}), \log (\mathrm{AUE}), \log (\mathrm{PDB})$ and $\log (\mathrm{PRMC})$ are cointegrated at the $5 \%$ threshold. They follow parallel evolutions over the period 1982 to 2017.

\subsection{The Estimation of the VAR Model}

In addition to highlighting the nature of the series, the determination of the optimal number of lags to be included in the estimation of VAR models is also fundamental.

\subsubsection{Determination of Lags Numbers}

To determine the optimal number of lags we used the Akaike and Schwarz criteria for lags ranging from 1 to 2 . Table 3 records the different values obtained for the different numbers of lags.

The number of lags selected corresponds to the lowest value of the criteria, i.e. $\mathrm{p}=2$.

\subsubsection{Estimation of VAR Model Parameters}

The estimate of the VAR(2) process is summarized in Table 4.

The first numbers in parentheses are the standard deviations and the second are the $t$ student of the estimated coefficients. The results indicate that Burkina Faso's cotton production delayed by two periods is negatively dependent on

Table 2. Johansen's cointegration test.

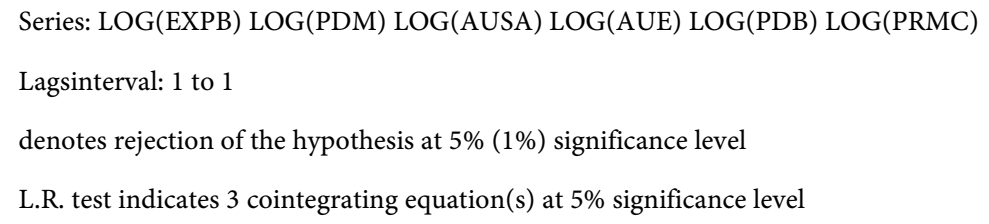

Source: Author, based on econometric estimation of data.

Table 3. Values of shorts numbers.

\begin{tabular}{ccc}
\hline Lags & Akaike & Schwarz \\
\hline 1 & 0.068 & 2.142 \\
2 & -4.204 & -0.336 \\
\hline
\end{tabular}

Source: The author, based on data estimation. 
Table 4. Model estimation VAR (2).

\begin{tabular}{|c|c|c|c|c|c|c|}
\hline Variables & $\begin{array}{c}\text { D (LOG } \\
(\text { EXP B)) }\end{array}$ & $\begin{array}{l}\mathrm{D}(\mathrm{LOG} \\
(\mathrm{PDM}))\end{array}$ & $\begin{array}{c}\text { D (LOG } \\
(\text { AUS A)) }\end{array}$ & $\begin{array}{l}\text { D (LOG } \\
(A \cup E))\end{array}$ & $\begin{array}{c}\mathrm{D}(\mathrm{LOG} \\
(\mathrm{PDB}), 2)\end{array}$ & $\begin{array}{c}\text { D (LOG } \\
(\text { PR MC)) }\end{array}$ \\
\hline \multirow[t]{3}{*}{$\begin{array}{c}\mathrm{D}(\mathrm{LOG} \\
(\operatorname{EXPB}(-1)))\end{array}$} & -0.387623 & 0.006342 & 0.890398 & 0.609546 & -0.869012 & -0.312396 \\
\hline & $(0.418768)$ & $(0.160165)$ & (1.998768) & $(0.413056)$ & $(0.520751)$ & $(0.42012)$ \\
\hline & $(-0.780121)$ & $(0.03774)$ & $(0.42998)$ & $(1.497889)$ & $(-1.51568)$ & $(-0.814802)$ \\
\hline \multirow[t]{3}{*}{$\begin{array}{c}\mathrm{D}(\mathrm{LOG} \\
(\mathrm{EXPB}(-2)))\end{array}$} & -0.410135 & 0.068897 & 2.268874 & -0.603814 & -0.628168 & 0.041155 \\
\hline & $(0.51973)$ & $(0.17143)$ & $(2.330422)$ & $(0.381042)$ & $(0.626972)$ & $(0.432871)$ \\
\hline & $(-0.68189)$ & $(0.44009)$ & $(1.07268)$ & $(-1.57048)$ & $(-1.23911)$ & $(0.09667)$ \\
\hline
\end{tabular}

Source: Author, based on data estimation.

European aid. However, they are positively dependent on U.S. subsidies, world cotton production, and world cotton prices.

\subsection{Interpretations of the Results of the Estimate}

First of all, it should be noted that the coefficients of a VAR model cannot be overemphasized because their economic interpretation is delicate, since all variables are considered and treated as endogenous ${ }^{13}$. Thus, a coefficient cannot be directly interpreted as a marginal effect, because by the dynamic definition of the model, the "all other things being equal" hypothesis does not hold in the medium or long term; a variation in one variable will affect the other variables in the model dynamically (Lütkepohl, 1993).

This is why these models are rather apprehended through shock response functions. These functions, insofar as they take into account the dynamic aspect of the system through inter-equation relations, are recognized as better summarizing the information contained in the data and as being more precise than coefficients (Canova, 2003).

The VAR models are thus analyzed through their dynamics via the simulation of shocks on the innovations of the variables. Shock response functions allow, according to Wold's Theorem (1938), to analyze the effect of a shock of an innovation on the current and future values of endogenous variables. Thus, for example, for variable $i$ reacting to a shock on variable $j$ at horizon $h$, this impact is given by: $\pi_{i h}=\frac{\partial E_{t}\left[y_{i t+h}\right]}{\partial \varepsilon_{j t}}$ with the vector of innovation.

The interpretations of the simulation results will therefore consist of the interpretation of the impulse reaction (response) functions and the variance decomposition.

${ }^{13}$ This is because these models are predictive and not "explanatory" models. 


\subsubsection{Interpretation of the Functions of Impulse Responses}

The model has been estimated with a delay for endogenous variables ${ }^{14}$ and rather than focusing on marginal impacts, we analyze, as is most often done, the VAR system through its dynamics via the simulation of shocks on the model's innovations.

Impulse reaction (response) functions therefore make it possible to analyze the impact of the variation of an innovation (the subsidies) on the variables in the model. This is why the analysis of VAR models is based on their dynamics through the simulation of shocks on the model's innovations.

Responses to shocks on the structural residuals of the six model variables are shown in Figures 1-4. For each variable, the shock is equal to the standard deviation of its residuals. The time horizon of the responses is set at 24 periods. This horizon represents the time required for the variables to return to their long-term levels ${ }^{15}$.

In the model, we have retained the subsidy variables (American and European subsidies) to simulate the shocks.

At the level of each graph, the response of the variables following a shock to American aid is shown in blue and that following a shock to European aid in red.

1) Reaction of Burkina cotton exports to U.S. and European subsidies.

Figure 1 shows the reaction of Burkina Faso's cotton exports to the effects of U.S. and European subsidies.

Figure 1 shows that a shock to U.S. subsidies results in a decline in Burkina Faso's cotton exports during the first four periods. Then, the effect becomes positive between the fifth and seventh periods. Then, from the eighth period onwards, we notice a fluctuating evolution of the effect before returning to its long term level from the twentieth period, where a certain stabilization takes place.

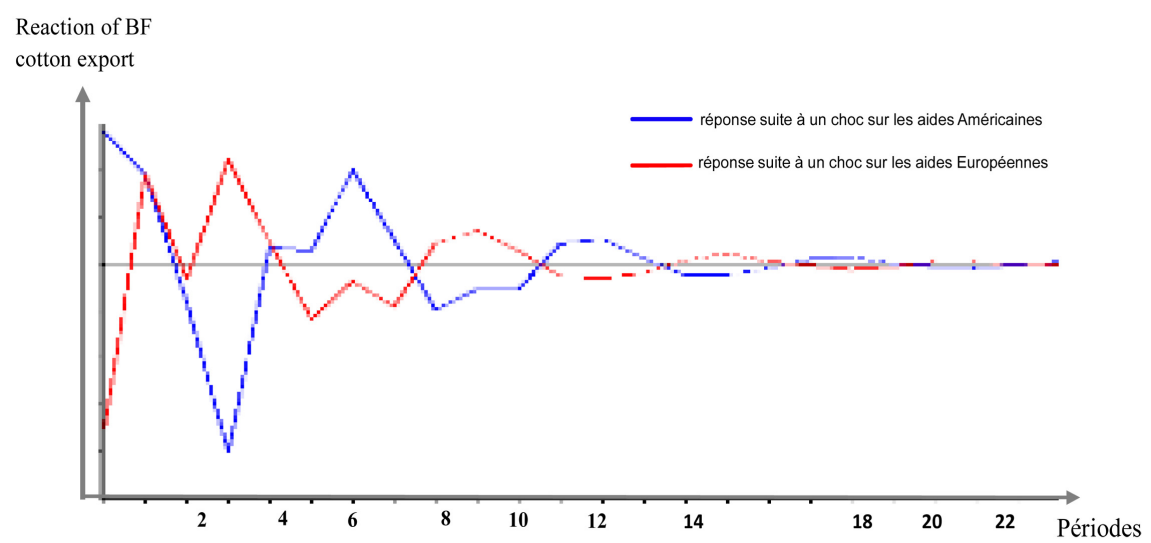

Figure 1. Reaction of Burkina cotton exports to US and EU subsidies. Source: Author, based on estimate data.

\footnotetext{
${ }^{14}$ The coefficients of the explanatory variables are not presented because they are of little interest in the VAR method due to their difficulty of interpretation, in particular due to the dynamic aspect of the system (Lütkepohl, 1993).

${ }^{15}$ Here assumed to be the equilibrium level.
} 
React of world

production of cotton

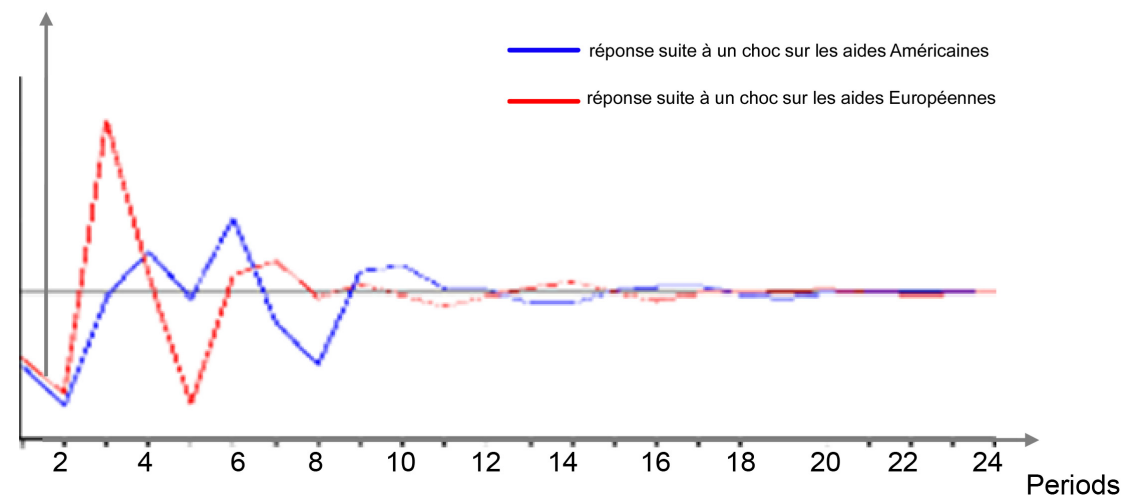

Figure 2. Reaction of world cotton production to US and EU subsidies. Source: Author, based on estimate data.

React of BF

cotton production

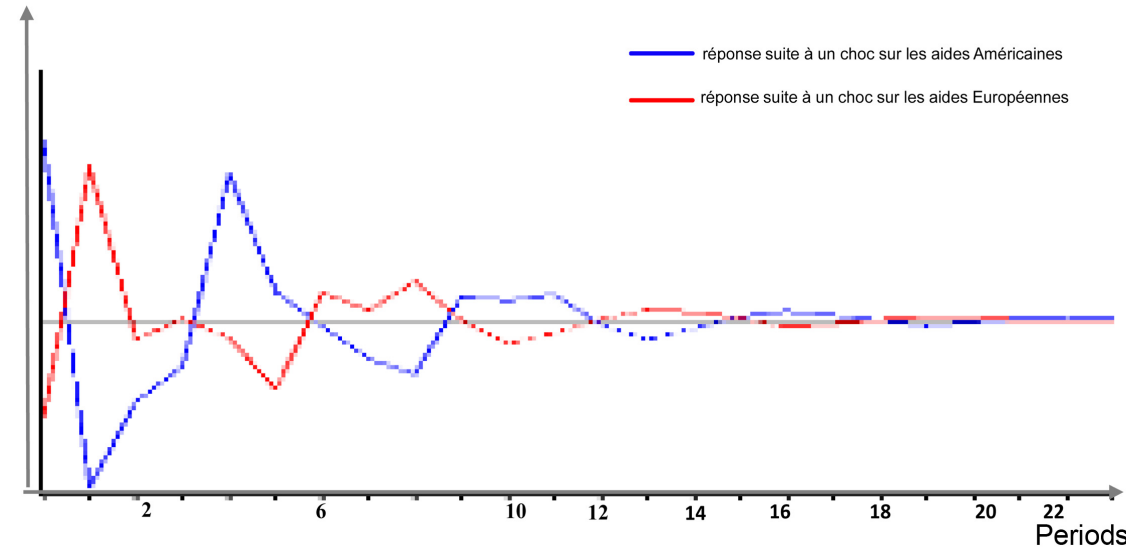

Figure 3. Reaction of burkina Faso's cotton production to U.S. and european subsidies. Source: Author, based on data estimate.

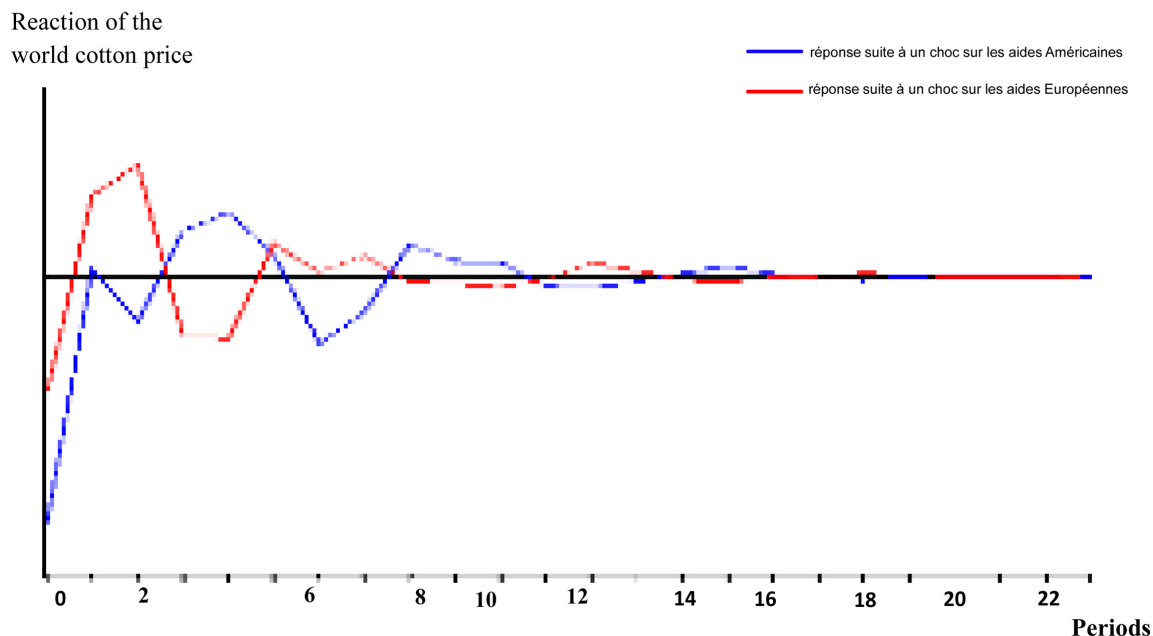

Figure 4. Reaction of the world cotton price to US and european subsidies. Source: Author, based on data estimate. 
On the other hand, it can be observed that following a shock on European subsidies, Burkina Faso's cotton exports initially react positively during the first three periods. Then, there is a jagged evolution from the fourth to the twentieth period, before stabilizing somewhat.

In general, the analysis in Figure 1 shows that over most of the analysis period, Burkina's cotton exports generally reacted instantly and negatively to a shock on U.S. and European subsidies. It can thus be seen that these subsidies have a negative impact on Burkina's cotton exports.

Another finding that emerges from the analysis of the figure is that, in general, the negative impact of US subsidies on Burkina Faso's cotton exports is greater than that of European subsidies (over the negative period). It can therefore be said that Burkina cotton exports are much more vulnerable to U.S. subsidies than to European subsidies.

2) Reaction of World Cotton Production to U.S. and European Subsidies.

As in the case of exports, Figure 2 illustrates the effects of American and European subsidies on world cotton production.

This graph shows that a shock to U.S. subsidies first results in an instant negative reaction of world cotton production during the first two periods. Then, the reaction becomes positive between the third and fifth periods. From the latter, we note a fluctuating evolution of the effect until the seventeenth period (with, however, more sustained declines than improvements), from which point it returns to its long-term level.

Moreover, a shock on European subsidies results in similar developments to those of US subsidies on world cotton production, with contrasting effects between the third and fifth periods. Indeed, it can be seen from the graph that between these two periods, US subsidies have a positive effect on world cotton production while the effect is negative for European subsidies.

But, overall, the analysis of Figure 2 leads us to say that U.S. and European subsidies have a negative impact on world cotton production in terms of the magnitude of the negative effects compared to the positive effects. Moreover, apart from the peak observed during the fifth period (negative effect of European subsidies on world production), it can be seen that US subsidies have a greater (negative) impact on the world cotton supply compared to that of European subsidies.

3) Reaction of Burkina Cotton Production to Subsidies.

The effects on cotton production in Burkina Faso as a result of U.S. and European subsidies are illustrated in Figure 3.

During the first two periods, the figure shows that the effects of an increase in U.S. subsidies on Burkina Faso's cotton production are negative. These effects become positive between the third and fifth periods before becoming negative again between the sixth and eighth periods. Overall, it can be noted that until the eighteenth period, the evolution of the effects is fluctuating with a peak (fifth period) and a low (ninth period). However, from this period onward, the effects of 
U.S. subsidies on Burkina Faso's cotton production tend to stabilize.

Considering also the importance of the negative effects of U.S. subsidies compared to the positive effects over the period, it is safe to say that these subsidies, overall, have a negative impact on Burkina Faso's cotton production.

Moreover, as can be seen in Figure 3, Burkina Faso's cotton production is increasing as a result of a shock to European subsidies during the first two periods. This production falls between the third and sixth periods but shows a contrasting trend between the seventh and eighteenth periods. From the latter period onward, the effects of European subsidies on Burkina cotton production tend to stabilize. It should also be noted that the evolution of the effects of these European subsidies contrasts with that of American subsidies, particularly between the fourth and eighteenth periods. However, overall, as with U.S. subsidies, the magnitude of the negative effects of European subsidies compared to the positive effects over the period had a negative impact on Burkina Faso's cotton production.

Ultimately, from this analysis of Figure 3, it appears that cotton production in Burkina Faso reacts negatively to a subsidy shock. It can therefore be said that U.S. and European subsidies have a negative impact on Burkina Faso's cotton production.

4) Reaction of the world cotton price following American and European subsidies.

From Figure 4, it can be noticed that the reaction of the world cotton price to US subsidies is instantaneous. The world cotton price increases sharply during the first two periods. The evolution of this price is then cyclical with upward and downward variations between the third and seventeenth periods. Then, the effect of subsidies on the world cotton price stabilizes after the eighteenth period. Overall, this analysis shows that the declines in the world cotton price outweigh the increases in the price of this product.

With regard to the effects of European subsidies, we note, as with the US subsidies, a positive improvement in the world cotton price over the first two periods of the analysis. On the other hand, the evolution of this price, following European subsidies, contrasts with that of American support between the third and sixteenth periods and stabilizes thereafter.

However, as with the US subsidies, overall, we can see that the decreases in the world cotton price outweigh the price increases resulting from European support. Through the dynamics of the VAR system, a positive shock on subsidies therefore results in a negative reaction of the cotton price.

It should be noted, however, that this result differs slightly from the conclusions of some previous studies, notably Shepherd (2004), who does not find a monotonous drop in price following a positive shock on subsidies.

In summary, U.S. and European subsidies are leading to recorded declines in Burkina Faso's cotton production, world cotton production, and Burkina's cotton exports, as well as a decline in the world cotton price. This drop in price 
leads "all other things being equal" to a drop in the world cotton supply and consequently a drop in Burkina Faso's cotton production.

Burkina Faso exports almost all of its cotton production. The effect of U.S. and European subsidies on Burkina Faso's cotton exports may therefore also result in a significant drop in cotton production (since the drop in world prices may discourage cotton growers from producing and there are not enough domestic outlets for cotton production).

From the analysis of the different figures, we note a relative delay of the system to regain equilibrium. This can be explained by the fact that we are in a case of agricultural supply. Indeed, in the production framework, agricultural activity uses fixed factors that often prevent it from adjusting in the short term. In other words, it will take some time for agricultural producers to retrieve market information and incorporate it into their production systems before equilibrium is restored.

\subsubsection{Decomposition of the Variance of the Prediction Error}

To calculate the contribution of innovations to the variance of the percentage error, the variance of the forecast error is decomposed.

When an innovation explains a significant part of the variance of the forecast error, it is inferred that the economy (or variable) under study is very sensitive to shocks affecting the series. In fact, the variance decomposition makes it possible to see which of the subsidies (American or European) has the greatest influence on the variables in the model. In this study, we considered the variables LEXPB, LPDB and LPRMC.

An analysis of the variance decomposition shows that 53.16 percent of the variations in Burkina Faso's cotton production are due in the very short term to variations in cotton exports, 32.33 percent to variations in U.S. subsidies and 8.97 percent to variations in European subsidies.

In the medium and long term, $42.96 \%$ of this variance is explained by EXPB innovations, $30.31 \%$ by AUSA innovations, $13.17 \%$ by AUE innovations and $9.12 \%$ by world price innovations.

It also shows that U.S. subsidies therefore have a greater impact on Burkina Faso's cotton production than European subsidies.

Table 5 shows that 75.34 percent of the variance in the forecasting error of Burkina's cotton exports is instantly due to its own innovations, 13.01 percent is due to U.S. subsidies, and 19.40 percent is due to European subsidies.

However, in the medium and long term, $48.19 \%$ of this variance is explained by its own innovations, $22.97 \%$ by those of US subsidies, $17.14 \%$ by innovations of European subsidies and $7.53 \%$ by changes in the world price of cotton.

There is some consistency between these results and those obtained on response functions following a subsidy shock. Indeed, it can be seen from the graphs that Burkina Faso's cotton exports react more to a shock on US subsidies than to a shock on European subsidies. Thus, U.S. subsidies have a strong influence on Burkina Faso's cotton exports. 
Table 5. Summary of variance decomposition (percent).

\begin{tabular}{|c|c|c|c|c|c|c|c|}
\hline \multirow{2}{*}{$\begin{array}{l}\text { Endogenous } \\
\text { variables }\end{array}$} & \multirow[b]{2}{*}{ Periods } & \multicolumn{6}{|c|}{ Exogenous variables } \\
\hline & & LEXPB & LPDM & LAUSA & LAUE & LPDB & $\begin{array}{c}\text { LPRM } \\
\text { C }\end{array}$ \\
\hline \multirow{2}{*}{ LEXPB } & 1 & 75.34 & 0 & 13.01 & 19.40 & 0 & 0 \\
\hline & 24 & 48.19 & 4.74 & 22.97 & 17.14 & 0.76 & 7.53 \\
\hline \multirow{2}{*}{ LPDB } & 1 & 53.16 & 2.69 & 32.33 & 8.97 & 1.19 & 0 \\
\hline & 24 & 42.96 & 3.86 & 30.31 & 13.17 & 1.93 & 9.12 \\
\hline \multirow[b]{2}{*}{ LPRMC } & 1 & 12.10 & 0.72 & 47.23 & 9.24 & 2.62 & 29.13 \\
\hline & 24 & 25.91 & 7.80 & 28.95 & 16.14 & 1.79 & 19.43 \\
\hline
\end{tabular}

Source: Based on estimate data.

With regard to the world price of cotton, its variations are mainly due to variations in US subsidies (47.23\%) in the very short term. Of these, $29.13 \%$ are due to its own innovations and $9.24 \%$ to those of European subsidies.

\section{Discussions and Recommendations}

The VAR modeling made possible to have a relatively suitable framework On the other hand, it is true that in recent years the world price of cotton lint has continued to decline downwards. However, this decline cannot be linked solely to the effects of American and European subsidies. In fact, in our opinion, other factors such as overproduction and the existence of large stocks of cotton in Asian countries, the arrival on the market of the cotton republics of the former USSR, the deterioration of the quality of cotton. African cotton (poor control of parasitism, lack of rigor in sorting at harvest time) the fall in the dollar rate (the reference currency of the cotton market) may be responsible for the current poor economic situation. For our work without resorting to an upstream economic theory, Impulse response functions lend themselves well to analyzing the consequences of a subsidy shock. Added to this is the simplicity of specification and estimation.

On the other hand, it is true that in recent years the world price of cotton lint has continued to decline downwards. However, this decline cannot be linked solely to the effects of American and European subsidies. In fact, in our opinion, other factors such as overproduction and the existence of large stocks of cotton in Asian countries, the arrival on the market of the former USSR republics cotton producers, the deterioration of the quality of cotton. African cotton (poor control of parasitism, lack of rigor in sorting at harvest time) the fall in the dollar rate (the reference currency of the cotton market) may be responsible for the current poor economic situation.

On the other hand, subsidies to cotton producers in the United States and in Europe could just as well be the consequence of the difficulties of the cotton market subjected to competition from synthetic fiber. Indeed, the cotton market 
is now subject to competition from synthetic fibers (polyester in particular) which could explain its sluggishness, in particular due to the drop in its price.

Moreover, in his analysis, (Shepherd, 2004), concerning the effect of American subsidies concluded that the colossal amour of United States subsidies, do not seem to have a significant impact in determining the price. world cotton. Likewise, the model used by the ICAC for price forecasts does not include the level of subsidies as an exogenous variable. This result, which concerns only American subsidies, could be different for Chinese subsidies, for example, which in recent years have also become important.

The result of (Shepherd, 2004) is also in line with the work of the World Bank which shows that developing countries are in agricultural products (including cotton) in general victims of tariff barriers and insufficient market access than subsidies to producers (World Bank, 2004).

The loss for Burkina Faso and African producers in general that has been discussed so far is the one linked to an abnormally low global price of cotton following distortions caused by subsidies from developed countries. But as we have seen with empirical studies, it is very difficult to assess this loss and we can even wonder about its existence. In this analysis, however, we may miss the main damage caused to African cotton producers, including Burkina Faso. In the gains that a country derives from international trade, the dynamic gains are the most important and this is particularly true for Burkina Faso. By specializing in cotton, Burkina Faso would benefit from increased efficiency but also from a sectoral dynamic where year after year productivity and competitiveness would improve. The increase in cotton harvests in the 1990s shows that major efforts have been made with clearly visible results even if the fall in world prices from 1995 has come to put an end to this boom in the Burkina Faso cotton sector, while the devaluation of the CFA franc in 1994 on the contrary gave hope of increased gains.

On the other hand, the risk for Burkina Faso cotton arises both from the dollar exchange rate which, when it is low, reduces the price received in CFA francs and from changes in Chinese demand. The combination of a weak dollar and a high amount of subsidies (leading to overproduction) could lead to a new crisis. In the longer term, the challenge facing the cotton sector in Burkina Faso is that of technological developments. Transgenic cotton already occupies half of the cultivated areas in developed countries such as the United States. Burkina Faso's competitiveness in the face of very capital-intensive productions is based on the characteristics of cotton, the yield or quality of which has so far not been able to be really improved by the selection of seeds. The lower quality of mechanical harvesting compared to manual harvesting also favors low-wage countries. This could be challenged by genetic engineering and improved harvesting techniques.

In order to face the crisis in the cotton sector, we believe that the need to diversify Burkina Faso's economy is desirable in the sense that the country's over-dependence on a single raw material whose price is very volatile is a brake 
on growth. The work (Turnovsky \& Chattopadhyay, 1998) shows that different types of volatility affect a country's growth, including the volatility of the terms of trade and production. The concentration of economic activity in a sector such as cotton increases these two types of volatility.

Nevertheless, we believe that the reduction of cotton subsidies is essential for the continuation of the reform of the sector in Burkina Faso. Success in liberalizing the sector and increasing its competitiveness can only be achieved in the context of a world market where the price signal is not distorted by subsidies.

In addition, we also believe that there is room for improvement in the competitiveness of the cotton sector in Burkina Faso by improving yields, input supply, crop quality and transport infrastructure. It is important that modernization efforts continue even in the absence of an early resolution of the issue at the WTO.

\section{Conclusion}

Like other poor countries in West Africa, Burkina Faso must work towards sustainable development and is counting on a cash crop: cotton. It is true that cotton revenues allow for socio-economic progress. They lead to a reduction in the number of people living below the poverty line. However, far from bringing economic independence and a capacity for autonomous development, cotton production (one of the main sources of national income) is impacted by agricultural subsidies from developed countries.

Analysis of our results shows that U.S. and European subsidies negatively impact Burkina Faso's cotton production as well as negatively influence the world price of cotton. Thus, any shock on subsidies has a negative impact on Burkina Faso's cotton production through a negative effect of subsidies on the world cotton price. The empirical results show for most cases a negative impact of subsidies on the world cotton price and thus a negative effect on Burkina cotton production.

With regard to exogenous factors, the question of exchange rates cannot be avoided if we want to address all the factors likely to influence the future of the sector in Burkina Faso and that of cotton-producing countries in general that are members of the Franc Zone. Thus, by engaging in traditional hedging operations, African exporters naturally protect themselves against short-term fluctuations, but not against market trends. Devaluation as an option in these situations is very unlikely at present, given the high social costs and the mixed record of the 1994 experience.

However, in our opinion, the challenges of the cotton sector and the measures to be taken in the medium and long term to avoid its collapse can be analyzed. For example, it is of paramount importance, if the difficulties of the cotton sector are to be resolved in the long term and if the conflicting interests of producers in developed and developing countries are to be reconciled, to continue to create opportunities for dialogue between the different categories of actors, with a view to identifying the measures best suited to the areas of trade and develop- 
ment.

With the evolution of the negotiations, somehow the disappearance of cotton subsidies may seem inevitable, the question being rather to know when this will happen. Cotton is now a symbolic issue at the WTO that serves as a test case for how the interests of developing countries can be taken into account by the institution. Indeed, observation of the cotton market shows that competitive countries like Burkina Faso do not find the place they should have in it, and the overall level of stocks and subsidies indicates that it is a market subject to various distortions.

The non-consideration of Chinese subsidies in this work constitutes a limit of the paper because China is the second country that subsidizes cotton after the United States of America.

Therefore, in terms of perspective for future work, the analyses could take into account Chinese subsidies.

In addition, this work could look at a world market without subsidies to see if the Burkinabe cotton industry could benefit from such a market.

\section{Conflicts of Interest}

The author declares no conflicts of interest regarding the publication of this paper.

\section{References}

Canova, F. (2003). Methods for Applied Research.

Doan, T., Litterman, R., \& Sims, C. (1984). Forecasting and Conditional Projection Using Realistic Prior Distributions. Econometric Reviews, 3, 1-100. https://doi.org/10.1080/07474938408800053

FAPRI (2002). The Doha Round of the World Trade Organization: Appraising Further Liberalization of Agricultural Markets. Working Paper 02-WP 317, Columbia, MI: Food and Agricultural Policy Research Institute, Iowa State University and University of Missouri-Columbia.

Fève, P. (2005). La modélisation macro-économétrique dynamique. Université de Toulouse (CNRS-GREMAQ et IDEI) et Banque de France (CRECH).

http://www.banqueFrance.fr

Goreux, L. (2003a). Les producteurs de coton des pays CFA face aux subventions américaines et européennes.

Goreux, L. (2003b). Prejudice Caused by Industrialized Countries Subsidies to Cotton Sectors in Western and Central Africa. Genève: OMC.

Goreux, L. (2003c). Reforming the Cotton Sector in Sub-Saharan Africa (2nd ed.). Africa Region Working Paper Series No. 62, Washington DC: World Bank.

Johansen, S. (1988). Statistical Analysis of Cointegration Vectors. Journal of Economic Dynamics and Control, 12, 231-254. https://doi.org/10.1016/0165-1889(88)90041-3

Leamer, L. (1972). The Paper Revolutionaries; the Rise of the Underground Press. New York: Simon and Schuster.

Litterman, R. B. (1980). A Bayesian Procedure for Forecasting with Vector Auto-Regression. Working Paper, Cambridge, MA: Massachusetts Institute of Technolo- 
gy, Department of Economics.

Lütkepohl, H. (1993). Introduction to Multiple Time Series Analysis. Berlin: Springer Verlag.

Nerlove, M. (1958). Estimate of Supply Elasticity: A Reply. American Journal of Agricultural Economics, 40, 723-727. https://doi.org/10.2307/1235381

ODI (2004). Understanding the Impact of Cotton Subsidies on Developing Countries and Poor People in Those Countries. London: ODI.

Pan et al. (2004). The impact of U.S. Cotton Programs on the World Market : An analysis of Brazilian WTO Petition. Working paper, USA: Texas Tech University.

Piggott, J., \& Whalley, J. (1980). Welfare Loss Estimates from Homeowner Tax Preferences: Inflation, Mortgage Interest Deductibility, and Capital Gains Treatment. Economics Letters, 6, 357-365. https://doi.org/10.1016/0165-1765(80)90010-5

Poonyth, D., Sarris, A., Sharma, R., \& Shui, S. (2004). The Impact of Domestic and Trade Policies on the World Cotton Market. Commodity and Trade Policy Research Working Paper, Rome, FAO.

Reeves, G., Quirke, D., \& Wyatt, S. (2001). Trade Distorsions and Cotton Markets: Implications for Global Cotton Producers. Canberra: Cotton Research and Development Corporation, Centre for International Economics.

Runkle, D. E. (1987). Vector Autoregressions and Reality. Journal of Business and Economic Statistics, 5, 437-442. https://doi.org/10.1080/07350015.1987.10509609

Shepherd, B. (2004). The Impact of US Subsidies on the World Cotton Market: A Reassessment. Paris: Groupe d'économie mondiale.

Sims, C. (1980). Macroeconomics and Reality. Econometrica, 48, 1-48. https://doi.org/10.2307/1912017

Sims, C., Stock, J., \& Watson, M. (1990). Inference in Linear Times Series Models with Some Unit Roots. Econometrica, 58, 113-144. https://doi.org/10.2307/2938337

Sumner, D. (2003). A Quantitative Simulation Analysis of the Impacts of U.S. Cotton Subsidies on Cotton Prices and Quantities.

Tockarick, S. (2003). Measuring the Impact of Distortions in Agricultural Trade in Partial and General Equilibrium Models. IMF WP/O3/110, Washington DC.

https://doi.org/10.5089/9781451853360.001

Turnovsky, S. J., \& Chattopadhyay, P. (1998). Volatility and Growth in Developing Economies: Some Numerical Results and Empirical Evidence. Seattle, WA: University of Washington.

Wold's Theorem (1938). Statistics-Econometrics-Forecasting. Office for Research Development and Education. http://www.xycoon.com

World Bank (2004). Cotton: Market Setting, Trade Policies, and Issues. Policy Research Working Paper.

Zellner, A. (1971). An Introduction to Bayesian Inference in Econometrics. New York: Wiley. 